\title{
Potential for Development of Medical Tourism in the Novosibirsk Region
}

\author{
Tatiana L. Chernysheva*

\begin{abstract}
Marketing and Service Department, Novosibirsk State Technical University, Novosibirsk, 630073, Russia *Corresponding author. Email: tablack@mail.ru
\end{abstract}

\begin{abstract}
The purpose of this study is to substantiate a platform for the development of incoming tourism as a point of growth in the economic and social situation of the Novosibirsk region. We view this platform, which distinguishes it favorably from other regions, as a combination of high-tech medical care, including diagnosis and treatment, with a belt of sanatorium-resort institutions, where a man can regain his strength. This article substantiates the assumption that the Novosibirsk region has all three components for establishing a medical cluster on its territory. These are scientific research companies conducting research in the field of medicine, medical care institutions and sanatorium-resort enterprises. This is a reliable platform for the development of medical tourism in the region. Medical tourism is just the kind of tourism that is literally aimed at improving human capital [1]. Tasks include identification of core resources for the development of medical tourism in the region, determination of priority actions to implement the project, as well as identification of major constraints to the development of medical tourism in the Novosibirsk region.
\end{abstract}

Keywords: medical tourism, tourism and recreation resources, traveller attraction, tourism infrastructure,

information-tourist center

\section{RESOURCES FOR THE DEVELOPMENT OF MEDICAL TOURISM IN THE NOVOSIBIRSK REGION}

In recent years, tourist flows in the Novosibirsk region have shown positive momentum. The area is not ignored by foreign tourists, especially Chinese. The flow of foreign tourists in 2015 amounted to 23,495 people, in 2016 43,075 people, in 2017 - 50,787 people, and in 2018 75,246 people. Speaking about Chinese tourists, in 2015 only 5,464 visits were registered, and in 2016 - 19801, in 2017 - 24,598, in 2018 - 29,086. [2]. In 2019, the Novosibirsk region was visited by about 40,000 Chinese people [3].

Of course, this is due to the region's rich resources which are favorable to many types of tourism, these are 2268 historical and cultural monuments; 24 reserves; 53 natural monuments; 11 ski resorts; 12 hunting bases; 259 hotels; 33 spa organizations; 103 recreation centers; 42 museums; 29 theaters [4]. However, I would like to pay especially close attention to medical tourism.

Medical tourism is an emerging phenomenon characterized by medical care combined with holiday making activities [5]. If it is to be interpreted as a combination of rehabilitation and rest procedures with the provision of highly qualified medical care, then it should be noted that the Novosibirsk region has all the conditions for the development of this type of tourism. There are conditions for creating a medical cluster here. Novosibirsk has a large number of research companies and universities conducting research in the field of medical materials and technologies, including the Institute of Nuclear Physics, the Institute of Cytology and Genetics, Novosibirsk State University, and Novosibirsk State Technical University. The well-known specialized institutions providing high-level medical care, needed by more than just residents of the region, include the Innovative Medical and Technological Center, the Novosibirsk branch of S.N. Fedorov NMRC "MNTK "Eye microsurgery", Academician E.N. Meshalkin Novosibirsk Research Institute of Circulation Pathology, Novosibirsk Research Institute of Traumatology and Orthopedics named after Ya.L. Tsivyan, Federal Center for Neurosurgery, Institute of Clinical Immunology, Research Center for Experimental and Clinical Medicine, Institute of Clinical and Experimental Lymphology, State Novosibirsk Regional Clinical Hospital, Road Clinical Hospital, City Clinical Hospital No. 1, No. 2, Regional Clinical Diagnostic Center, SB RAS Central Clinical Hospital. The main competencies in the field of medicine in the Novosibirsk region include as follows: replacement arthroplasty, eye microsurgery, cardiovascular surgery, in vitro fertilization (IVF), oncology, dental services. The main health indicators in the Novosibirsk region are increasing from year to year [6].

\section{MEASURES FOR THE DEVELOPMENT OF MEDICAL TOURISM IN THE REGION}

Currently, priority areas of work of regional authorities to further improve the quality of medical services have been identified. The region intends to establish two vascular centers; within the framework of the fight against cancer, 
the Center for Radiation Medicine named after S. Berezin is under construction in the region. Since 2020, the Novosibirsk region will join the implementation of the priority federal project "Development of air ambulance" [7].

It was noted that in order to undergo medical treatment in the city's medical institutions, more and more foreigners are coming, whose most popular procedures are manipulations in the following areas: cardiac surgery, orthopedics, eye surgery [8].

A tourist arriving in Novosibirsk to receive planned medical care also has the opportunity to undergo a rehabilitation course in one of the numerous specialized health-improving institutions of the region. The Novosibirsk region is a lake region with more than 3,000 lakes, of which the most famous are Karachi, Krasnozernoye, Danilovo, Gorkoye. The Novosibirsk region has 16 deposits of sapropelic therapeutic muds in the Kolyvan, Bolotninsky and Ubinsky areas.

According to the Decree of the Government of the Russian Federation No. 534 dated 06/11/2016, it was recommended to supplement the federal target program "Development of domestic and inbound tourism in the Russian Federation for 2011-2018" with the objectives to create tourist and recreational clusters in 17 regions of the federation. In the Novosibirsk Region, because of many healing lakes, the Ozerny cluster on Lake Karachi is intended to become such a zone of accelerated development.

In the Novosibirsk region there are many resorts being popular with residents of the city and the region. First of all, these are: Sosnovka, Krona, Lesnaya Skazka, Ob volna, Parus, Baraba, Sibiryak, Zhemchuzhina, Zolotoy bereg, Rassvet, Morozovo , Borvikha, Zdorovye, Izumrudny, Lazurny, Yeltsovka, Vostok, Berezka, Dovolensky, Krasnoozersky, Ob Zori, Bylina, Balush, Dubrovino, Zdravnitsa, Sinemorye. In addition, the region is distinguished by unique tourist and recreational facilities to be included in tourist routes. These include the Wolf's Mane (Kargatsky District), Berdsky Rocks (Iskitimsky District), Barsukovskaya Cave (Maslyaninsky District), Mochan (Bagansky District), the Place of Battle of Prince Kuchum with a detachment of Cossacks near the river Irmen (Ordynsky district), Chichaburg (Zdvinsky district), village Egoryevskoe, Bugotak hills (Toguchinsky district), Umrevinsky ostrog (Moshkovsky district), Belovsky waterfall (Iskitimsky district), Kolyvan crafts house.

The scheme of activities to include these facilities in the tourist turnover is as follows: tourist facility analysis - study

\section{REFERENCES}

[1] M.Z. Bookman, K. R. Bookman, Medical Tourism in Developing Countries, England: Palgrave, 2007 p. 22. DOI: https: //doi.org/ 10. 1057/9780230605657

[2] Number of foreign tourists to the Novosibirsk region in 2018 grew by one and a half times, Novosibirsk. Without format, URL: of target markets to come up with a proposal - tourist infrastructure on site building - search for promotion channels.

It is known that $90 \%$ of tourists traveling for medical purposes want to learn something new, $83 \%$ of them travel with a satellite. Thus, there is a solid audience, which stay in the city and the region shall be properly organized [9]. Obviously, it is necessary to create a specialized agency of medical tourism on the platform of one of Novosibirsk universities that train specialists in tourism and social and cultural services. The agency should be authorized to design turnkey individual medical tours. Based on the database of medical and health facilities of the region and the identified needs of a particular client, he is offered first to undergo treatment in a particular medical center of the city, and then to undergo rehabilitation in a particular health resort of the region corresponding to the profile of his disease. The region has sanatoriums aimed at treating diseases of the musculoskeletal system, nervous, cardiovascular and respiratory systems, and the gastrointestinal tract. Throughout the whole period of the client's stay in the region, he is interacted and provided with comprehensive assistance (various medical documents, insurance, ordering transport, providing tickets, cultural and educational programs during rehabilitation). To implement this project, it is necessary to take the following priority steps: 1) to develop an analytical basis for the development of medical tourism in the Novosibirsk region; 2) to develop unique tours based on tourist and recreational resources of the Novosibirsk region and contributing to its positioning; 3 ) to initiate public-private partnership projects; 4) to establish preferences for subjects of the tourist area in the region.

The main problems hindering the development of medical tourism in the Novosibirsk region include the lack of wellstructured information on capabilities of the region's medical centers for potential foreign patients, especially from Central Asia, Kazakhstan and China, the language barrier, visa restrictions, as well as request of foreign patients for compliance of medical facilities to international standards. It is necessary to improve the skills of advising patients on the recommended methods of surgical and nonsurgical treatment [10], drawing up a price certificate and a destination route through online technologies. The patient shall be provided with comprehensive support - starting with paperwork and ending with travel organization.

https://novosibirsk.bezformata.com/listnews/novosibirs kuyu-oblast-v-2018-godu/72836543/, Retrieved 14.12.2019

[3] 40000 Chinese residents visited Novosibirsk region in 2019, URL: https://www.nso.ru/news/39325,

Retrieved 22.01.2019

[4] Novosibirsk region in numbers, Territorial Authority of the Federal State Statistics Service for the Novosibirsk Region, Novosibirsk, 2015 
assembly of the Novosibirsk region, URL:

[5] T. Ghosh, S. Mandal Medical Tourism Experience: Conceptualization, Scale Development, and Validation, Journal of Travel Research 2019, V 58,Issue 8, pp. 1288-1301. DOI: https: //doi.org/ 10.

1177/0047287518813469

[6] Key indicators of health care in the Novosibirsk region,

URL:http://novosibstat.gks.ru/wps/wcm/connect/rosstat _ts/novosibstat/resources/.pdf, Retrieved 02.02.19

[7] Novosibirsk Region will engage in the development of air ambulance, Siberian Region,

URL:http://sibkray.ru/news/1/918532/?sphrase_id=313 0224, Retrieved 02.02.19

[8] Sore points. Travnikov designated problems of the Novosibirsk health care system, Sheets of Legislative http://vedomosti nso.rf/, Retrieved 29.01.2019

[9] N. H. Abd, H. Hussin, P. N. J. Kassim, R. Alavi, Z. Dahari, Medical Tourism Service Quality: Finally Some Findings, Total Quality Management and Business Excellence, 2015, V. 26, Issue 9-10, pp. 1017-1028. DOI: https: //doi.org/ 10. 1080/14783363.2015.1068597

[10] A. de la Hoz-Correa, F. Munoz-Leiva, The role of information sources and image on the intention to visit a medical tourism destination: a cross-cultural analysis, Journal of travel and tourism marketing, 2019, V.36, Issue 2, pp. 204-219. DOI: https: //doi.org/ 10. 1080/10548408.2018. 1507865 